\title{
Exploratory Evidence of Sex-Dimorphic Associations of the Ulna-to-Fibula Ratio, a Potential Marker of Pubertal Sex Steroid Exposure, with the Implicit Need for Power
}

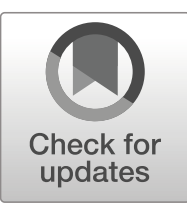

\author{
Martin G. Köllner ${ }^{1}$ (D) Kira Bleck $^{1,2}$
}

Received: 20 January 2020 /Revised: 2 March 2020 / Accepted: 3 March 2020

Published online: 17 March 2020

(C) The Author(s) 2020

\begin{abstract}
Objectives We propose a novel marker of pubertal organizing hormone effects on the brain, long bone length, and assess its relationships to implicit motives, especially the implicit need for power ( $n$ Power).

Methods In a partly exploratory approach, we tested 126 participants (after exclusions; 53 men, 73 women), in a cross-sectional design using the Picture-Story Exercise ( $n$ Power, activity inhibition), standard anthropometric measurements (BMI, height), and calipers to assess bone length of the ulna and fibula.

Results Results indicated that a sex-dimorphic $(d=0.55)$ Ulna-to-Fibula Ratio (UFR), which is independent of body height, best captures the variance in our data. While we did not find bivariate relationships between long bone length and $n$ Power, a sexdimorphic interaction of $n$ Power and activity inhibition on UFR-asymmetry (UFR $\mathrm{U}_{\mathrm{r}-1}$; right versus left UFR) emerged. High $\mathrm{UFR}_{\mathrm{r}-\mathrm{l}}$ scores were related to the inhibited power motive (high $n$ Power, high activity inhibition) in men, while for women the pattern was (non-significantly) reversed. In addition, UFR was predicted by a sex-dimorphic effect of $n$ Power, with low UFR scores being associated with a higher $n$ Power in men and a tendency for high UFR scores being related to lower $n$ Power in women.

Conclusions We discuss our results regarding UFR's potential as a sex-dimorphic marker of the organizing effects of pubertal steroid hormones on the motivational brain beyond hand and face parameters routinely used in current research. Finally, we examine how our findings fit recent results obtained for the relationship between 2D:4D digit ratio or facial width-to-height ratio and $n$ Power.
\end{abstract}

Keywords Long bone length · Implicit motives · Organizing hormone effects · Power motive $\cdot$ Puberty $\cdot$ Ulna-to-fibula ratio

Martin G. Köllner

martin.koellner@fau.de

Extended author information available on the last page of the article 


\section{Introduction}

This paper presents the Ulna-to-Fibula Ratio (UFR), a novel possible indicator of pubertal organizing hormone effects, permanent organizing effects of steroid hormones on the structure of the nervous system during development (Sisk and Zehr 2005). We also use UFR to add to the growing literature pointing to influences of organizing hormone effects on the development of implicit motives (see Köllner et al. 2019, for an overview), motivational dispositions operating outside of conscious awareness that promote the attainment of specific incentive classes and the avoidance of specific disincentive classes by amplifying the affective quality of these (dis)incentives (Schultheiss and Köllner 2020).

Lasting organizing hormone effects during sensitive developmental windows on the nervous system and thus the adult behavior of an organism were first observed by Phoenix et al. (1959), who reported masculinized mating behavior of female guinea pigs after prenatal treatment with androgens. A large body of research in humans demonstrates effects of organizing hormone effects on phenomena like athletic prowess (Hönekopp and Schuster 2010), dominance, or reproductive success (Manning and Fink 2008). In recent years, it has been established that pubertal hormone levels also organize behavior in humans and non-human animals (Schulz and Sisk 2016; Shirazi et al. 2020; Sisk and Zehr 2005). For example, meta-analytic evidence suggests small, but observable links between indicators of pubertal testosterone and male aggression (Haselhuhn et al. 2015) as well as to dominance behavior across both sexes (Geniole et al. 2015).

Due to ethical restrictions and to allow for cross-sectional study designs, organizing hormone effects in humans are often assessed retrospectively via markers of steroid hormone exposure. These markers take advantage of the fact that during development, the brain and the growth of specific parts of the body are simultaneously affected by the same organizing hormones, enabling estimates of the contribution of organizing hormone effects to the development of certain braindependent behaviors and dispositions (cf. Hönekopp et al. 2007). Several markers have been proposed, most prominently the second-to-fourth-digit length ratio (2D:4D; e.g., Manning 2002; Manning et al. 1998) for prenatal steroid hormone exposure, i.e. the fetal ratio of estradiol (E2) to testosterone (T) (Lutchmaya et al. 2004), and facial width-to-height ratio (fWHR; Carré and McCormick 2008; Weston et al. 2007), the ratio of bizygomatic width to upper face height, for pubertal $\mathrm{T}$ and perhaps also for E2 exposure (Janson et al. 2018).

A central feature of markers is sex dimorphism, which suggests that they reflect sex differences in hormone exposure during development and thus may also be able to capture more gradual differences in organizing hormone exposure between individuals within each sex. While this is clearly the case for 2D:4D, with the ratio being smaller for men than for women (Hönekopp and Watson 2010; Zheng and Cohn 2011), it is less so for fWHR.

Meta-analyses have demonstrated that fWHR, previously implicated to be tied to sexual selection and the evolution of human faces (Weston et al. 2007) and used as the flagship marker of pubertal organizing effects in humans, shows only a weak (Geniole et al. 2015; men > women) and possibly even a non-existent (Kramer 2017) 
dimorphism. Thus, it is time to look for new markers with robust dimorphism and predictiveness for behavioral and dispositional criteria (Köllner et al. 2018), especially for the pubertal stage. One such marker may be found by moving away from the traditional sites of marker research - hand and face - and turning to the body at large instead. Here, long bone length clearly is a hormone-sensitive feature. For example, neonatal E2 injection has a negative impact on femoral length in adult mice (Connelly et al. 2015).

As sexual dimorphism in overall body shape and size is readily visible to the naked eye, it is surprising that marker research often focusses on rather subtle variations in finger (2D:4D) or facial (fWHR) ratios. While there are some attempts to measure indicators like waist-to-hip ratio, body mass index (Fink et al. 2003), or body weight and height (Deaner et al. 2012), research has not yet made full-fledged use of this potential.

Long bone growth in the hands, arms, and legs has already been linked to sexual preferences and this was explained by the amount of sex steroid exposure during development (Martin and Nguyen 2004). Sex differences in bone growth appear during puberty and include a bigger skeleton, higher peak bone mass, and greater bone size in men compared to women (see Callewaert et al. 2010, for an overview). If women and men show differences in skeleton size, an obvious target of marker research should be long bone growth. The growth of long bones differs in size, robustness, and length, with men typically scoring higher than women on these dimensions and with the sex difference being most obvious on the latter one (Sacragi and Ikeda 1995). Thus, and also because long bone length was already discussed as a marker of steroid exposure in earlier research (Martin and Nguyen 2004), we chose bone length as our marker candidate in the present study.

\section{Steroid Hormones and Long Bone Growth}

The skeletal sexual dimorphism emerging during puberty raises the question if sex steroids are involved in sexually dimorphic bone growth, as their concentrations rise markedly during this developmental stage (Ober et al. 2008). Indeed, connections exist between organizing influences on linear bone growth and sex hormones like estrogens and androgens (see Juul 2001, for an overview; cf. Cutler 1997). Although the actual pattern is complex, with a pronounced role of the growth hormone/insulin-like growth factor1 (GH-IGF1) axis and androgen-to-estrogen conversion via aromatase in men (for an overview of the mechanisms involved, see Callewaert et al. 2010), the contribution of sex steroids is undisputed.

One of their most crucial contributions during puberty is the biphasic dose-response dependent relationship of estrogens to linear bone growth (Cutler 1997). For men and women alike, low concentrations drive the growth spurt during puberty, stimulate GH secretion, as well as promote long bone growth velocity, but high concentrations are involved in the closure of the epiphyses, thus terminating linear bone growth (Cutler 1997; Juul 2001). $\mathrm{T}$ in turn affects bone growth in a similar way as estrogens (Vanderschueren et al. 2004). Besides activating the androgen receptor, $\mathrm{T}$ can be converted into 17ß-estradiol (E2) via aromatization (Callewaert et al. 2010).

As girls have an eight times higher concentration of E2 than boys even before the onset of puberty and this is a probable explanation of their earlier epiphyseal maturation (Cutler 1997), sexual dimorphism in overall body height is not surprising. In addition, 
differences in long bone length between individuals within and across both sexes may indicate differential exposure to sex steroids during puberty.

In sum, we conclude that (1) high pubertal levels of E2, as well as of $\mathrm{T}$ that is subsequently converted to E2, entail shorter long bones in adulthood. Thus, (2) these shorter long bones in adults should be useful as a marker of pubertal exposure to sex steroids. Finally, if sex steroids are involved in bone growth, then (3) bone length in adulthood should also be eligible as a marker of organizing hormone effects on the brain and the behavioral dispositions it mediates.

\section{The Implicit Need for Power}

One such disposition that has repeatedly demonstrated associations with markers (see Köllner et al. 2019, for an overview) of prenatal (i.e. 2D:4D; Schultheiss 2017; Schultheiss et al. 2019; Schultheiss and Zimni 2015) and pubertal (i.e. fWHR; Janson et al. 2018) markers of steroid hormone exposure is the implicit need for power (nPower). $n$ Power is a capacity for deriving pleasure from impact on others, be it physically, mentally, or emotionally, and, conversely, experiencing others' impact on oneself as aversive (Schultheiss and Köllner 2020). It is one of the most wellresearched implicit motives besides the implicit need for achievement (nAchievement), a capacity for deriving pleasure from autonomously mastering challenging tasks, and the implicit need for affiliation (nAffiliation), a capacity for deriving pleasure from establishing, maintaining, and restoring positive relationships (Schultheiss and Köllner 2020). Implicit motives have an affect-amplifying quality that guides responses to punishment and reward (cf. Atkinson 1957; Schultheiss and Köllner 2014, 2020).

Implicit motives are not consciously accessible (Schultheiss and Köllner 2020) and meta-analyses demonstrate no substantial relationships to explicit, self-report-based motives of the same domain (Köllner and Schultheiss 2014; Spangler 1992). Thus, implicit motives are measured with the Picture-Story Exercise (PSE; McClelland et al. 1989), a story-telling method using pictures of social situations as stimuli. The PSE typically shows high interrater reliability when two or more independent coders score the same story material and satisfactory test-retest reliability (with the latter ranging from .71 for 1 day to .25 for 10 years; see meta-analysis by Schultheiss and Pang 2007). ${ }^{1}$

Stories are scored according to content-coding systems causally validated (cf. Borsboom et al. 2004) by arousing an implicit motive in one experimental group, but not in another, and distilling systematic between-group differences into coding systems (see Schultheiss and Köllner 2020; Schultheiss and Pang 2007).

Due to the repeatedly found links to organizing hormone effects as captured by 2D:4D and fWHR, we focus on $n$ Power in the present study. $n$ Power shows predictive validity regarding biological (e.g., susceptibility to illness; Jemmott 1987; McClelland et al. 1980), individual (e.g., implicit learning in contest situations; Schultheiss et al. 2005), and societal phenomena (e.g., initiation of wars; Winter 1993).

\footnotetext{
${ }^{1}$ Please note that internal consistency measures like Cronbach's Alpha used to evaluate questionnaires are not applicable to PSE measurement. The PSE is a stimulus-response-instrument with the pictures representing social situations and the stories to these pictures are treated as behavioral output, with the variability between pictures representing a key criterion of the PSE's validity (for details, see Schultheiss and Schultheiss 2014; for an in-depth treatment of the PSE's reliability, see Schultheiss and Pang 2007; for a demonstration of how PSE scores with higher variability show even better predictive validity, see Reuman 1982).
} 
Results involving implicit motives are often moderated by activity inhibition (AI), measured by counting the negation "not" in the PSE-stories. Individuals high in AI show functional brain lateralization favoring the right hemisphere especially during stress (Schultheiss et al. 2009). Jointly high levels of $n$ Power and AI, the inhibited power motive (IPM), are associated with a context-appropriate, sophisticated expression of $n$ Power (Schultheiss and Köllner 2020) and thus with more successful functioning in social situations, as documented in studies of persuasive communication or managerial success (McClelland and Boyatzis 1982; Schultheiss and Brunstein 2002; Steinmann et al. 2015).

\section{Links between $n$ Power and Steroid Hormones}

Most importantly, $n$ Power shows functional connections to sex steroids (Schultheiss 2013). For example, in contest situations, men high in $n$ Power show $\mathrm{T}$ increases after winning and $\mathrm{T}$ decreases after losing (Schultheiss et al. 2005) and a similar pattern emerges for women's $n$ Power and E2 in contest situations (Stanton and Schultheiss 2007; see Köllner et al. 2019, for an overview).

Recent marker research showed that $n$ Power may be shaped by organizing hormone effects during development (see Köllner et al. 2019, for an overview and a tentative developmental model of nPower). Regarding prenatal E2-to-T ratio, Schultheiss and Zimni (2015, $N=50)$ were the first to report associations between a low, "male-typical" 2D:4D and the IPM. A large-scale replication (Schultheiss et al. 2019, $N=618$, four sub-studies) robustly confirmed a relationship between digit ratio and the IPM: The asymmetry of right and left $2 \mathrm{D}: 4 \mathrm{D}, \mathrm{D}_{\mathrm{r}-\mathrm{l}}$, as indicator of prenatal sex steroid exposure (marker direction: positive for estrogens, negative for T; Manning et al. 2014) was associated with the IPM in a sex-dimorphic way. Women high in the IPM showed a "male-typical" (high prenatal T and/or low E2) asymmetry-pattern (left 2D:4D larger than the right one), with a reversed (non-significant) pattern for men. Together, these observations point to prenatal effects of sex steroids on brain areas involved in human motivation (see Schultheiss et al. 2019, for a detailed discussion).

Most importantly for our research regarding pubertal organizing hormone effects, Janson et al. (2018) reported positive associations between a "male-typical" high fWHR as an established marker of pubertal steroid exposure ( $\mathrm{T}$ and perhaps also E2) and the IPM in a large sample $(N=213)$. Similar to the results by Schultheiss et al. (2019), the findings were sex-dimorphic. Again, women with "male-typical" marker scores were high on the IPM. This unexpected result was tentatively explained with $n$ Power being a non-declarative, broad disposition that goes beyond aggressive or isolated dominance displays usually examined in fWHR research.

As all studies including markers and $n$ Power so far obtained results for the IPM, AI as an indicator of functional brain lateralization in favor of the right hemisphere (Schultheiss et al. 2009) is a potential moderator variable to include in our study. A tentative explanation for AI's pervasive impact are contributions of prenatal and perhaps also pubertal organizing hormone effects to brain lateralization: Prenatal $\mathrm{T}$ disadvantages left compared to right hemispheric development (Geschwind and Galaburda 1987), which may also affect lateralization of prefrontal cortex (PFC) functions involved in human dominance behavior, and the PFC in turn undergoes further circuitry changes in adolescence (see Köllner et al. 2019, for details). 
In sum, $n$ Power has functional connections to sex steroids like E2 in women and T in men and seems to be partly rooted in prenatal and pubertal organizing hormone effects of these hormones (Köllner et al. 2019; cf. Köllner and Janson 2017). Considering the latter fact and that E2 and $\mathrm{T}$ are also responsible for organizing effects on linear bone growth, $n$ Power represents a valid choice for further exploring markers of organizing hormone effects of the motivational brain. AI needs to be considered while exploring such effects, as it consistently moderated the relationships between $n$ Power and markers of organizing hormone effects in previous studies.

\section{Overview of the Present Research}

With the aims of searching for a new marker of pubertal organizing hormone effects and adding to the growing body of research of associations of implicit motives with such markers of organizing hormone effects, we measured bone length of ulna and fibula in healthy young adults after assessing implicit motives and AI with the PSE.

\section{Selected Long Bones}

Ulna and fibula were chosen, as they are sexually dimorphic long bones. Sex determination via the ulna has been studied for more than 60 years and can be applied in the forensic sciences, as male ulnae are larger than female ones (Purkait 2001). The fibula in turn can be used in osteoarchaeology to determine the sex of a skeleton, and the high accuracy allows using sex determination based on the fibula in forensic medicine and physical anthropology (larger values for men compared to women; Sacragi and Ikeda 1995). Thus, ulna and fibula should represent valid choices for our anthropometric study.

In addition, we aimed at bones that are measurable on the body surface without the need for participants to undress in the lab, which disqualified bones like the clavicle or the femur. Moreover, ulna and fibula are easier to measure in humans (see measurement details below). Finally, humans are tetrapods with pentadactyl limbs (Kherdjemil et al. 2016) which places the bones of the forearm (ulna, radius) and of the shank (fibula, tibia) in an ontogenetic analogy. This homology of ulna and fibula, as well as their equivalent position on the limb, makes comparisons between the two appropriate.

\section{The Present Study}

In a first step, we introduce long bone length as a possible marker of pubertal organizing hormone effects. To this end, we report its descriptive properties, test for sexual dimorphism as a prerequisite for a bone parameter to be the target of organizing effects of sex steroids, and try to combine the acquired long bone length data into a composite indicator that should be independent of body size and capture the complexity of the data without too much information loss. For example, we will test if the marker signal as reflected in sexual dimorphism resides on the upper and/or the lower limb, as an analogy to 2D:4D (a bone measure, too) research, where the second digit is used as a control variable for overall size while the fourth digit is the actual marker signal carrier (Schultheiss et al. 2019).

Regarding organizing hormone effects on the motivational brain, we expected a negative correlation between $n$ Power and long bone length (in our study: ulna, fibula; 
Hypothesis 1). As $n$ Power already showed relationships to fWHR as a marker of pubertal steroid exposure, a connection to another possible indicator of pubertal exposure seemed plausible. The assumed negative direction derives from the positive functional association between $\mathrm{T}$ (men) and E2 (women) and $n$ Power later in life combined with the negative impact of high E2 (or high T converted to E2 via aromatase) on long bone length through epiphyseal closure during growth. We expected this relationship for both measured bones and both sexes.

Second, we expected bone length to be predicted by an interaction pattern involving sex, $n$ Power, and AI, as well as bone type (ulna, fibula) and body side (left, right; Hypothesis 2). While sex emerged as a moderator in well-powered studies (Janson et al. 2018; Schultheiss et al. 2019), $n$ Power and AI produced results in all studies on motives and markers so far (including Schultheiss and Zimni 2015). Schultheiss et al. (2019) found a five-way interaction additionally involving body side (left, right) and bone (second digit and fourth digit in Schultheiss et al. 2019; ulna and fibula in our research), and thus these variables deserve scrutiny in our study, too. Due to the complex nature of such a possible five-way interaction, we are not well-positioned to predict specific directions or patterns of the effect and use Hypothesis 2 only to test variables that are likely relevant to the association.

Other motives may also be influenced by organizing hormone effects, as Schultheiss et al. (2019) report some effects of $n$ Achievement on average digit ratio. In addition, Schultheiss and Zimni (2015) already observed an (albeit non-significant) association of $r=.17$ between $n$ Affiliation and a "female-typical" high 2D:4D (but see Schultheiss et al. 2019). Thus, we will explore relationships between $n$ Achievement and $n$ Affiliation and bone length.

\section{Method}

\section{Sample}

Overall, 134 individuals were tested. Five participants were excluded because of previous knowledge regarding individual tasks. All remaining participants met the minimum criteria for interpretable PSEs (average story length above 30 words, no missing stories; Janson et al. 2018; see Smith 1992). Three of them stated they had previously written stories to the pictures presented in the PSE on a routine question in the demographic questionnaire. However, they were not excluded, as their final PSE-scores were within +/-3SDs of the sample and they registered no hit on a suspicion check item. Finally, three additional individuals were excluded due to a $\mathrm{BMI} \leq 17.5$, as this may have interfered with normal long bone growth or indicate that their growth period was not finished (see e.g. Russell 1985, for effects of anorexia nervosa on human growth). The final sample consisted of 126 participants (53 men, 73 women), aged 18 to 30 years $(M=21.54 ; S D=3.14)$. We had decided a priori that only individuals in this age range would be allowed to participate to test adults only who had not entered further significant hormonal changes like the menopause. Another reason was that fWHR as a bone-based marker is known to decrease with age (Hehman et al. 2014) and we wanted to rule out undesired noise due to age in our analyses on long bone length. 


\section{Design}

We tested our predictions in a 2 (Bone: ulna vs. fibula) $\times 2$ (Side: left vs. right) $\times 2$ (Sex: male vs. female) design with bone and side as within-subjects and self-reported sex as between-subjects categorical variables. Body height (log-transformed to improve normality) was a covariate assessed via anthropometry to control for overall size differences not specifically attributable to long bone length. $n$ Power and AI were continuous predictors, assessed with the PSE (these two variables were absent in the reduced model describing the marker properties of our long bone measure). The dependent variable was bone length, assessed via anthropometry. The design was correlational with one single testing session.

\section{Materials}

\section{Implicit Motives}

Implicit motives were assessed with the PSE, using standard instructions (see Schultheiss and Pang 2007) and a standard set of six pictures (e.g., Pang and Schultheiss 2005 ) in randomized order, presented for $10 \mathrm{~s}$ each: women in laboratory, boxer, trapeze artists, couple by river, ship captain, and nightclub scene. Participants had 4 min to write an imaginative story in response to each picture in an on-screen window.

PSE stories were coded by two trained coders in the PSE-Coder software (Frisch and Schultheiss 2012) according to the Manual for scoring Motive Imagery in Running Text (Winter 1994). Extended coding rules were used (Köllner 2015; cf. Janson et al. 2018), omitting the two-sentence-rule and allowing for multiple motive-subcategories within one sentence, but not for the same subcategory repeatedly unless separated by an instance of another main motive. $n$ Power is scored for strong, forceful actions, controlling others, attempts at persuasion, providing unsolicited help, impressing or eliciting strong emotions in others (for coding subcategories for $n$ Affiliation and $n$ Achievement, please see Winter 1994). The frequency of the German negation "nicht" ("not", necessary for determining AI) and word count per story were determined by PSE Coder.

The two coders previously exceeded $85 \%$ intercoder reliability for all three motives in practice material prescored by experts (Schultheiss 2009). Motive codings were first added up for every motive domain for each participant. After determining interrater reliability, which was good with .77 for $n$ Achievement, .85 for $n$ Affiliation, and .80 for $n$ Power (Pearson correlations of raw scores), motive scores were averaged between raters. Scores for all motives and AI deviated from normality and were thus square-root transformed after adding a constant of one. Transformed scores were all significantly correlated with word count $(r \mathrm{~s}>.26 ; p \mathrm{~s}$ $<.01)$ and thus residualized for this variable by regression and subsequently converted to $z$ scores.

\section{Anthropometric Measurements}

Except for the removal of jackets and shoes, participants were fully dressed during the anthropometric measurements. For ulna and fibula measurements, a precision caliper 
was used (Metrica 12040, maximum measuring range: $50.00 \mathrm{~cm}$, precision: $0.02 \mathrm{~mm}$ ). We selected measurement points that were easily and painlessly measurable, exist in every human, and are unmistakable for other reference points: caput ulnae and olecranon for the ulna and caput fibulae and malleolus lateralis for the fibula. Fibula measurements were performed on sitting participants with the knee angled at $90^{\circ}$ and the lower leg standing vertically on the ground. For ulna measurements, participants were asked to remove jackets and watches, and if possible to pull the sleeve of pullovers etc. up over the elbow. The second author built an arm-length-measuring-apparatus (ALMA; see Fig. 1), a wooden frame to be placed on a table with a holding for the sliding caliper and a back wall against which the sitting participant places his forearm. ALMA was placed in a $45^{\circ}$ angle towards the participant and the height of the caput ulnae was marked on a sheet of paper affixed to the back wall. One slider of the fixed caliper was then brought to the height of the marking to obtain ulna length (for details on measurement and apparatus, equipment illustrations, and further references regarding long bone measurement, see the guide by Bleck 2018). Measurements were performed by three independent raters, with two raters per individual participant, achieving high interraterreliability (bivariate Pearson correlations; $n \mathrm{~s}>31, p \mathrm{~s}<.001$ ) ranging from .91 to .99 for ulna and from .81 to .95 for fibula (cf. Bleck 2018). Body height was assessed with a measuring tape affixed to a wall, weight with a SOEHNLE scale.

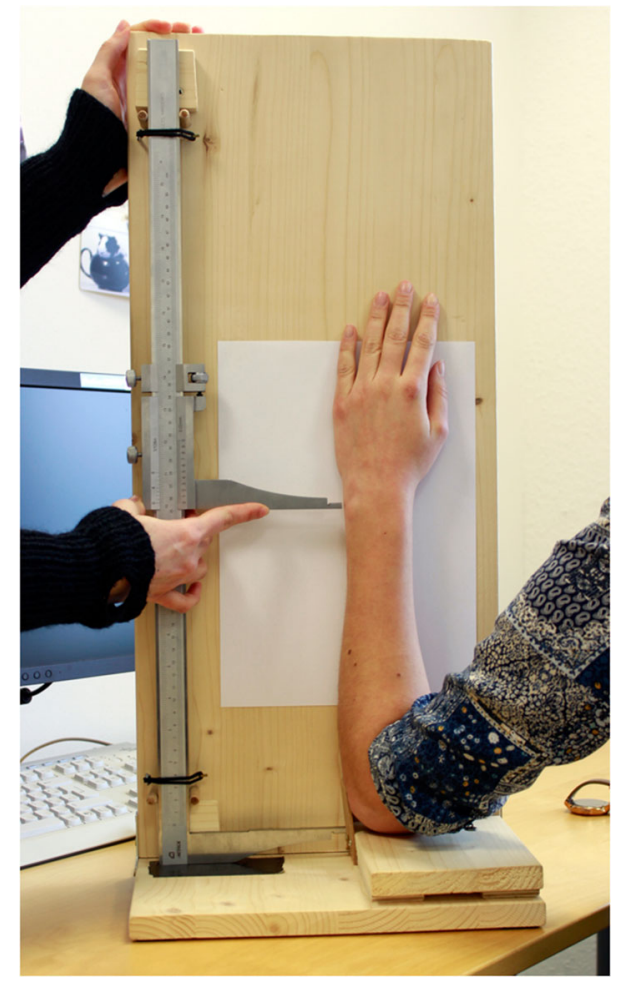

Fig. 1 The arm-length-measuring-apparatus (ALMA) used in the present study. Figure available at https://osf. io/afmrg, under a CC-BY4.0 license 
Participant sex and age was assessed via self-report in a demographic questionnaire at the end of the PC-based part of the experiment.

\section{Procedure}

Participants were tested in October and November 2015. Informed consent was obtained and participants were seated in separated cabinets. The order of the computer-administrated tests was identical for all participants: The PSE was run first to avoid undesired, systematic prior motive-arousal via other tasks (Schultheiss and Pang 2007). After several tasks unrelated to the research questions examined here, demographic variables were assessed via a questionnaire. Participants then underwent several anthropometric measurements before being fully debriefed.

\section{Statistical Methods}

We tested our predictions using Systat (Version 13) and with Pearson correlations as well as general linear models.

\section{Results}

\section{Data Preparation}

Aside from the above-mentioned transformations on PSE-variables, log-transformation was performed for height, BMI, and age to improve normality. Ulna ${ }_{\text {res }}$ and fibula ${ }_{\text {res }}$ resulted from residualizing the respective bone lengths for log-transformed body height and $z$-standardizing the residuals. Ulna-to-fibula ratio (UFR) was computed by dividing uncorrected ulna length by uncorrected fibula length.

\section{Descriptive Statistics}

Because this is the first study linking measurement of long bones like ulna or fibula to motivational variables, we provide full overall (Table 1) and within-sex (Table 2) descriptive statistics. In general, there were robust associations between body parameters, which may be due to covariance with overall body size. There were negative associations between $n$ Power and $n$ Affiliation (persisting marginally within sexes) and between $n$ Achievement and AI. Associations between ulna and fibula length or body size with $n$ Affiliation are spurious and due to women's lesser height and greater affiliation motivation (Drescher and Schultheiss 2016). Correspondingly, these relationships vanish within each sex (Table 2).

Sex differences were observed for $n$ Power, with higher values for men compared to women, with the reverse being true of $n$ Affiliation. Men also had longer ulna and fibula bones, but this finding did not survive correction for body height for fibula and dropped to trend-level for ulna. In addition, men in this sample had on average a higher BMI than women.

Looking at interrelationships between our variables of interest within each sex, besides a negative relationship with $\mathrm{AI}, n$ Achievement was negatively related to 


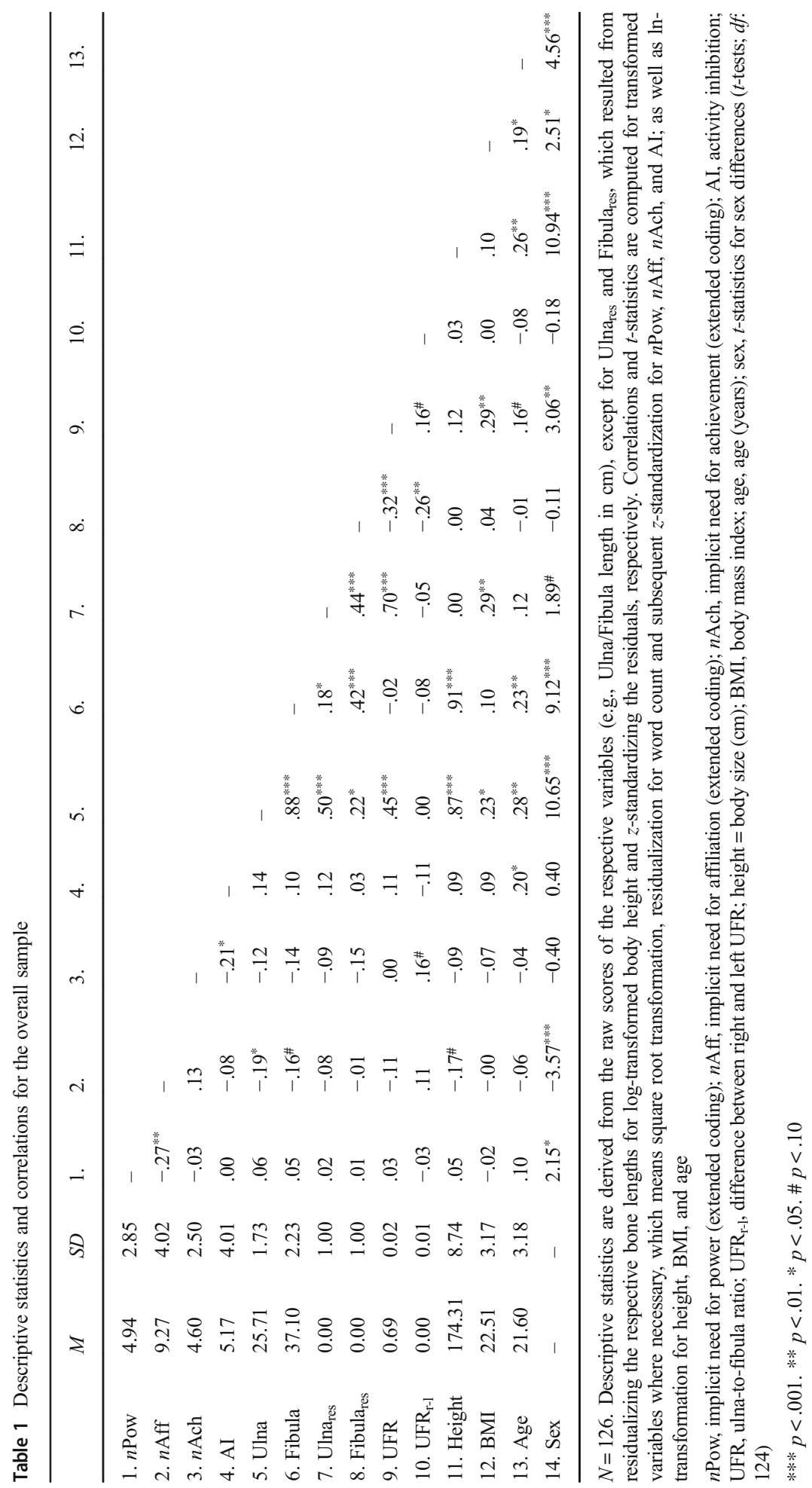




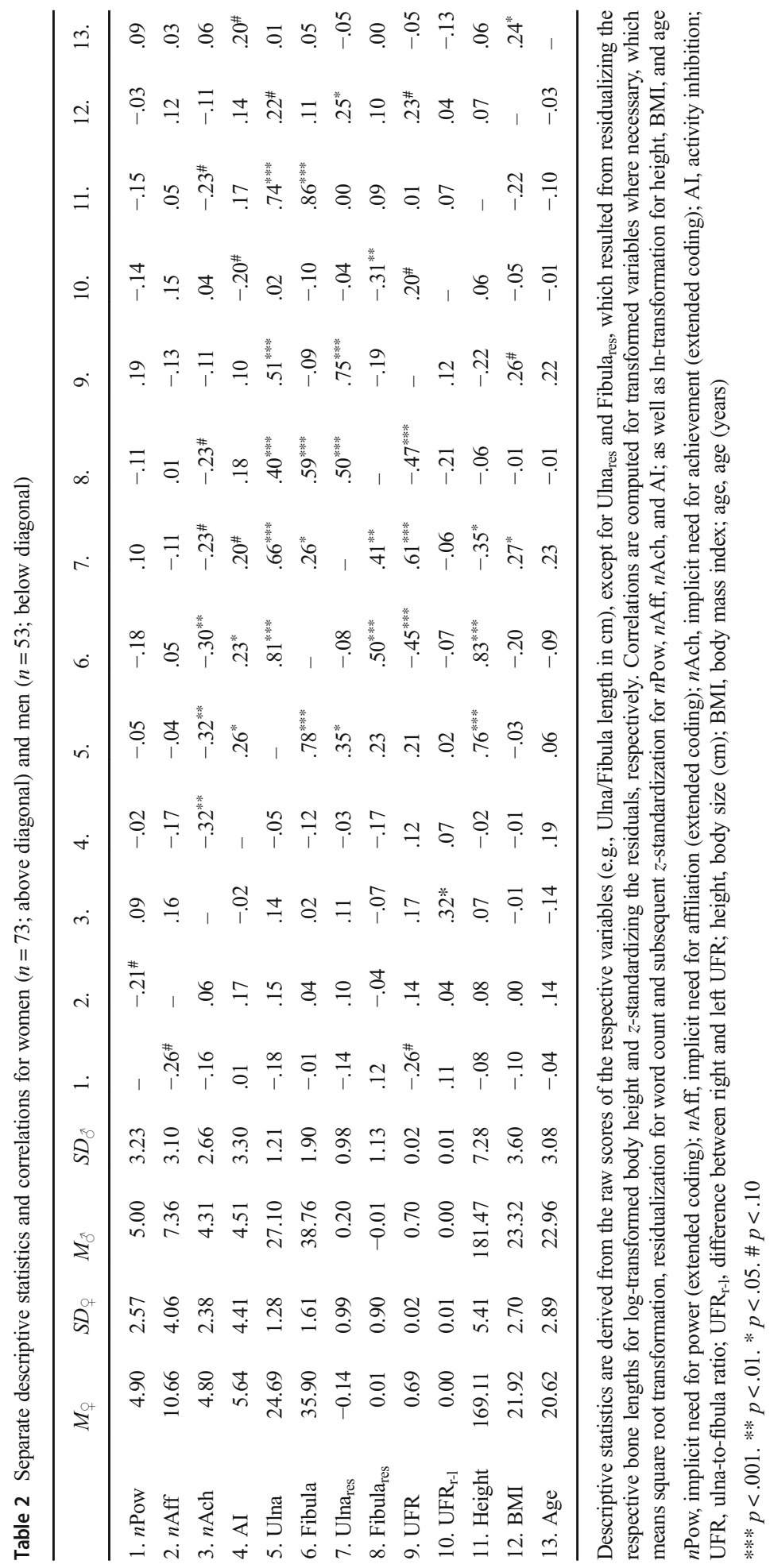


untransformed as well as (marginally to) transformed ulna and fibula length and body height in women. For women, AI was significantly related to ulna and fibula length, and marginally to corrected ulna length.

\section{Hypothesis Testing}

\section{Marker Properties of Long Bone Length}

Our first goal was to establish whether long bone length is sexually dimorphic, whether one or both limbs carry a meaningful marker signal, and how the complexity associated with two bones and two body sides could be meaningfully distilled into a novel marker. Regarding sexual dimorphism, Table 1 reveals sexual dimorphisms in both ulna and fibula. However, only ulna remained (marginally) sexually dimorphic after partialling out body height and thus was conceived of as the signal carrier, while fibula might be used as a correction for general differences in bone length affecting the entire body.

Our reduced model including bone, side, and sex as predictors for long bone length while controlling for body height essentially confirmed the ideas resulting from the descriptive statistics: Consistent with earlier research showing no bilateral difference between long bone characteristics (see ulna research by Purkait 2001), no overall Bone $\mathrm{x}$ Side $\mathrm{x}$ Sex interaction emerged $\left(F(1,123)=0.41, p=.52, \eta_{\mathrm{p}}{ }^{2}=.003\right)$ and side was not involved in any lower-order effect $(F \mathrm{~s}<0.60, p \mathrm{~s}>.44)$. However, a Bone $\mathrm{x}$ Sex interaction emerged $\left(F(1,123)=6.68, p=.01, \eta_{\mathrm{p}}{ }^{2}=.052\right)$. Splitting the main model by bone (which had produced a significant main effect in the main model: $F(1,123)=$ $\left.30.00, p<.001, \eta_{\mathrm{p}}{ }^{2}=.196\right)$ then revealed a pronounced effect of sex on long bone growth for the ulna $\left(F(1,123)=7.16, p<.01, \eta_{\mathrm{p}}{ }^{2}=.056\right)$, but not for the fibula $\left(F(1,123)=0.02, p=.88, \eta_{\mathrm{p}}{ }^{2}=.0002\right)$.

In sum, the most meaningful way of reducing the data seems to be averaging within limb over both sides and then treating ulna as the signal carrier and fibula as a longbone "control" limb. In analogy to the 2D:4D bone ratio - but placing the signal carrier in the numerator instead of the denominator for easier interpretability - UFR was thus computed by dividing ulna length by fibula length. UFR was predicted by sex while controlling for body height ${ }^{2}$ in a reduced model, $F(1,123)=8.74, p=.004, \eta_{\mathrm{p}}{ }^{2}=.066$. UFR was normally distributed $(W=.99, p=.36$; see Fig. 2, see Tables 1 and 2 for descriptive statistics) and highly significantly sex-dimorphic, with larger values for men compared to women $(p=.003)$ and an intermediate size of this effect $(d=0.55)$. Within each sex, UFR was marginally negatively related to male $n$ Power already on a bivariate level, while closely missing trend-level for a positive association to female $n$ Power $(p=.10$; see Table 2).

As Schultheiss et al. (2019) reported findings pertaining to the IPM for $\mathrm{D}_{\mathrm{r}-\mathrm{l}}$, we mirrored this approach: $\mathrm{UFR}_{\mathrm{r}-1}$ was thus constructed as the difference between right and left UFR (see Tables 1 and 2, and Fig. 2 for descriptive properties). UFR r-l $_{\text {was }}$ normally distributed $(W=.98, p=.07)$, but not sexually dimorphic $(p=.86)$. It was

\footnotetext{
${ }^{2}$ We controlled for body height in subsequent models to avoid undesired noise due to potential differential growth rates of upper/lower limbs with increasing body height (see Leslie 2019, for an analogous argument regarding 2D:4D). However, statistical conclusions in models using UFR or $\mathrm{UFR}_{\mathrm{r}-1}$ were unchanged regardless of controlling for body height or not, except where otherwise indicated, making these variables marker candidates independent of body height.
} 

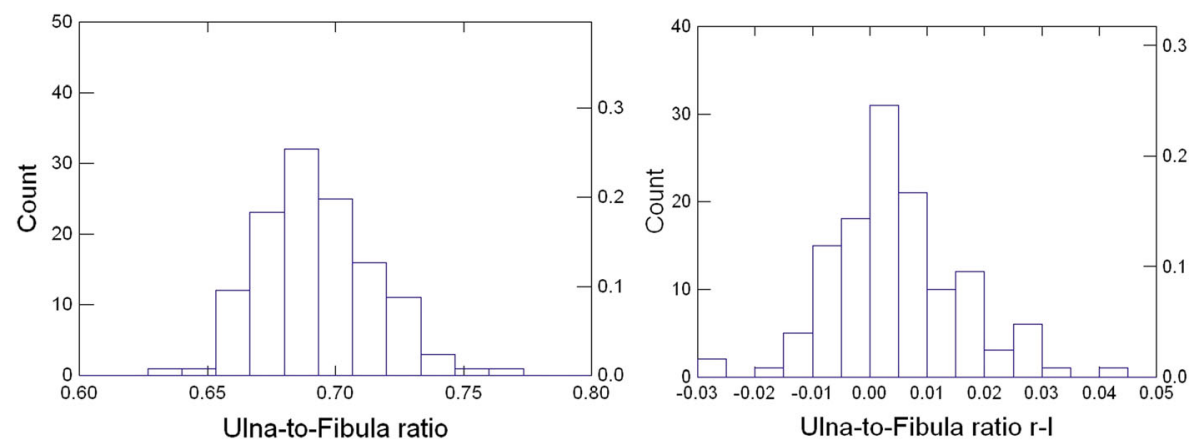

Fig. 2 Histograms for Ulna-to-Fibula ratio (UFR) and $\mathrm{UFR}_{\mathrm{r}-\mathrm{l}} \cdot \mathrm{UFR}_{\mathrm{r}-1}$ represents the difference between right and left UFR. Figure available at https://osf.io/afmrg, under a CC-BY4.0 license

positively related to $n$ Achievement for men and marginally so for the whole sample. Overall and for women, $\mathrm{UFR}_{\mathrm{r}-\mathrm{l}}$ was negatively related to Fibula ${ }_{\text {res }}$ and marginally positively to UFR. Only for women, a marginally negative relationship to AI emerged. ${ }^{3}$

\section{Associations to $n$ Power}

$n$ Power did not show bivariate negative relationships to the uncorrected or the heightadjusted lengths of ulna and fibula (see Tables 1 and 2). This was true for the overall sample as well as within each sex, even if the negative relationships for the male ulna $(p=.19)$ and the female fibula $(p=.12)$ approached trend level. Hypothesis 1 was not supported.

Regarding Hypothesis 2, caution is advised, because side failed to produce any effects in the reduced model without PSE variables. Nevertheless, in support of Hypothesis 2, we found an overall Bone $\mathrm{x}$ Side $\mathrm{x}$ Sex $\mathrm{x} n$ Power $\mathrm{x}$ AI interaction $\left(F(1,117)=5.90, p=.02, \eta_{\mathrm{p}}^{2}=.048\right)$.

We simplified the interaction by replacing individual bones by UFR for each side and obtained a Side (left vs. right UFR) $\mathrm{x}$ Sex $\mathrm{x} n$ Power $\mathrm{x}$ AI interaction $(F(1,117)=$ $\left.4.70, p=.03, \eta_{\mathrm{p}}{ }^{2}=.039\right)$. We further simplified the pattern by using $\mathrm{UFR}_{\mathrm{r}-1}$ as dependent variable, with the Sex $\mathrm{x} n$ Power $\mathrm{x}$ AI interaction remaining significant $\left(F(1,117)=4.70, p=.03, \eta_{\mathrm{p}}^{2}=.039\right)$. A final model split by sex revealed a $n$ Power $\mathrm{x}$ AI interaction on $\mathrm{UFR}_{\mathrm{r}-1}$ in men $(B=0.004, S E=0.002, t(48)=2.05, p<.05$, $\Delta \mathrm{R}^{2}=.08$ ), with a high $\mathrm{UFR}_{\mathrm{r}-1}$ related to the IPM (see Fig. 3). For women, no

\footnotetext{
${ }^{3}$ Another criterion to establish the validity of a possible new marker of organizing hormone effects or to determine its constituting developmental window may be its convergent validity with established markers. As parts of our data were used as one study in the two-study aggregation by Janson et al. (2018), we were able to compute the correlation of UFR and $\mathrm{UFR}_{\mathrm{r}-1}$ with fWHR in our sample. Regardless of the approximation chosen (brow, eyelid, or nasion; for details please see Janson et al. 2018), there were significant associations between $\mathrm{UFR}_{\mathrm{r}-1}$ and fWHR, $r \mathrm{~s}<-.18, p \mathrm{~s}<.05$. When using $2 \mathrm{D}: 4 \mathrm{D}$-data assessed from handscans (HP Scanjet G3010) via ImageJ from Franziska Jägel's bachelor thesis within the same project, there were significant associations between UFRr-1 and overall $(r=.18, p<.05)$ as well as left $(r=.19, p=.03)$ 2D:4D, with a similar, but not significant finding for the right hand $(r=.13, p=.14)$.For UFR without the asymmetry information, there were no convergent findings $(|r \mathrm{~s}|<.08, p \mathrm{~s}>.38)$. Overall, this is another indicator of the possible value of $\mathrm{UFR}_{\mathrm{r}-1}$ as a potential marker integrating the body variables (bone, side) postulated in Hypothesis 2. However, with regard to the developmental window, the pattern leaves room for the possibility of a prenatal, a pubertal, or a combined marker.
} 

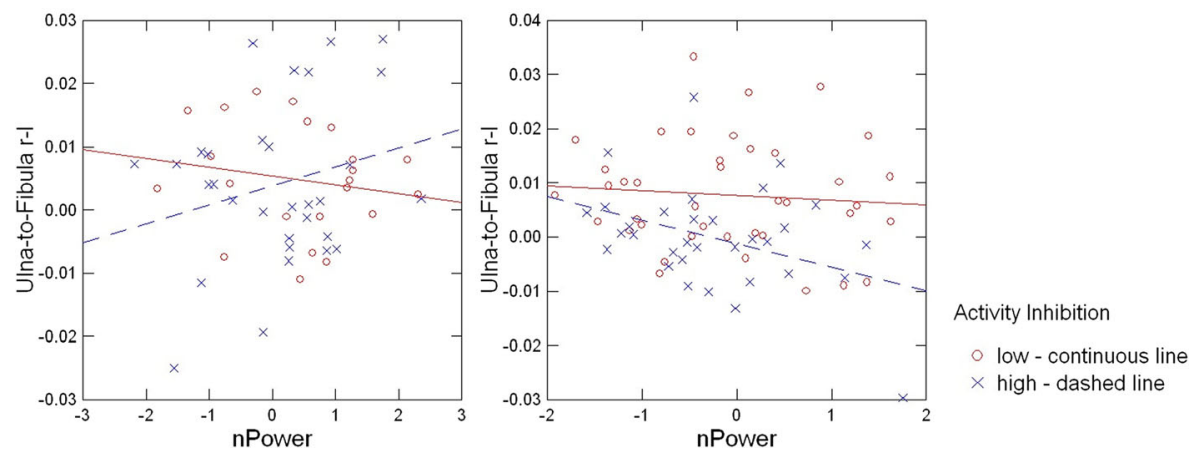

Fig. 3 Relationship between the implicit need for Power ( $n$ Power) and Ulna-to-Fibula $\mathrm{r}_{\mathrm{r}-1}\left(\mathrm{UFR}_{\mathrm{r}-\mathrm{l}}\right)$ dependent on activity inhibition (AI) for men (left) and women (right; one outlier removed). UFR $\mathrm{r}_{\mathrm{r}-1}$ represents the difference between right and left Ulna-to-Fibula ratio. $n$ Power was square root transformed, residualized for word count and subsequently $z$-standardized. The same was true for AI (median split). Figure available at https://osf. io/afmrg, under a CC-BY4.0 license

$n$ Power $\mathrm{x}$ AI interaction on $\mathrm{UFR}_{\mathrm{r}-1}$ emerged $(B=-0.001, S E=0.001, t(68)=-0.90$, $p=.37, \Delta \mathrm{R}^{2}=.01$ ), but the IPM-pattern was reversed (see Fig. 3). The direction of $\mathrm{UFR}_{\mathrm{r}-\mathrm{l}}$ 's relationships to the IPM pointed to a "male-typical" pattern for men and "female-typical" pattern for women (the sign for "male-typical" UFR values is positive, not negative as for 2D:4D). However, caution is advised due to the insignificant result in women and UFR $\mathrm{r}-1^{\text {'s }}$ lacking dimorphism in this sample.

Thus, we focused on more robust, easier-to-replicate lower-order effects. As this is the first paper to report associations between implicit motive measures and long bone growth, we only pursued significant $(p<.05)$ effects involving PSE variables emerging in the overall model including all factors. These effects were a Bone x Sex x $n$ Power $\left(F(1,117)=7.00, p<.01, \eta_{\mathrm{p}}{ }^{2}=.056\right)$ and a Side $\mathrm{x}$ Sex $\mathrm{x}$ AI interaction $(F(1,117)=$ $\left.4.11, p=.04, \eta_{\mathrm{p}}{ }^{2}=.034\right)$. Follow-up analyses including only those variables involved in each effect revealed the following:

First, the Bone $\mathrm{x}$ Sex $\mathrm{x} n$ Power interaction persisted in a reduced model, $F(1,121)=6.34, p=.01, \eta_{\mathrm{p}}^{2}=.050$. Follow-up analyses revealed marginal Bone $\mathrm{x} n$ Power interactions in male $\left(F(1,50)=3.64, p=.06, \eta_{\mathrm{p}}{ }^{2}=.068\right)$ and female participants $\left(F(1,70)=3.05, p=.09, \eta_{\mathrm{p}}^{2}=.042\right)$. To illustrate the nature of the within-sex interaction patterns, we simplified the factor Bone by representing ulna and fibula length as UFR. Controlling for body height, we found that this simplified model captured the sex dimorphic relationship between bone growth and the power motive well, as reflected in a Sex $x n$ Power interaction on UFR scores $\left(F(1,118)=6.18, p=.01, \Delta \mathrm{R}^{2}=.045\right.$; see Fig. 4). In subsequent analyses, UFR was significantly negatively related to $n$ Power for men $(B=-0.01, S E=$ $\left.0.003, t(50)=-2.07, p=.04, \Delta \mathrm{R}^{2}=.08\right)$ and marginally positively related to $n$ Power in women $\left(B=0.005, S E=0.003, t(70)=1.68, p=.096, \Delta \mathrm{R}^{2}=.04\right) .{ }^{4}$

\footnotetext{
$\overline{4}$ These sub-analyses were the only instance were statistical conclusions for UFR-related results changed when dropping body height as a control variable, with UFR's relationship with $n$ Power dropping to marginal significance $(p=.06)$ for men and to the marginal significance threshold for women $(p=.10$, see Table 2$)$. However, as the overall Sex $x n$ Power interaction on UFR kept its $p$ value $(p=.01)$, slopes for men and women differed anyway.
} 


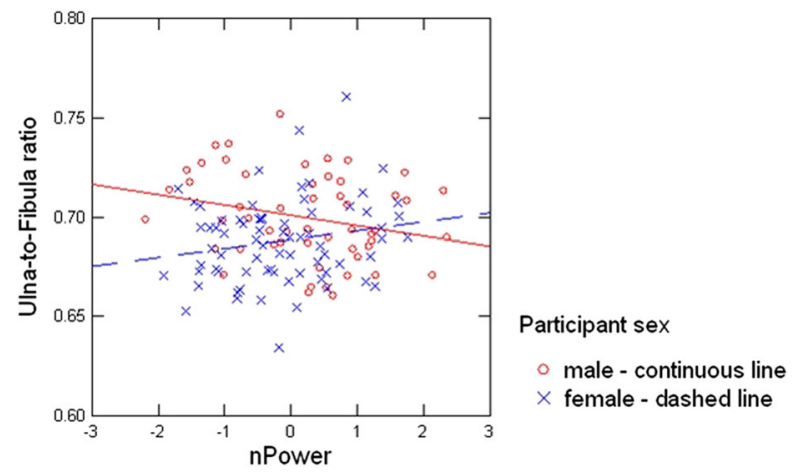

Fig. 4 Scatter-plot showing the sex-dimorphic associations between implicit need for power ( $n$ Power) and ulna-to-fibula ratio (UFR) by participant sex. $n$ Power was square root transformed, residualized for word count and subsequently $z$-standardized. Figure available at https://osf.io/afmrg, under a CC-BY4.0 license

Thus, $n$ Power was higher in men with a relatively shorter ulna and longer fibula, with a reversed, albeit weaker pattern (relatively longer ulna and shorter fibula) for women.

Second, the Side x Sex x AI interaction persisted at the .05 threshold in a simplified model, $\left.F(1,121)=3.90, p=.05, \eta_{\mathrm{p}}{ }^{2}=.031\right)$. Correspondingly, we found a Side $\mathrm{x}$ AI interaction in men $\left(F(1,50)=5.32, p=.03, \eta_{\mathrm{p}}{ }^{2}=.096\right)$, but not in women, $F(1,70)=0.0002, p=.99, \eta_{\mathrm{p}}^{2}=.000003$. However, follow-up analyses for men for both sides were inconclusive (for details, see supplemental at https://osf.io/afmrg) and thus this effect was not pursued further.

\section{Exploratory Analyses}

Almost all results for two explicit questionnaires, the Personality Research Form (PRF; Stumpf et al. 1985) and the Picture-Story Exercise Questionnaire (PSEQ; Schultheiss et al. 2011) were non-significant and are reported in the supplemental at https://osf.io/afmrg.

We also reran the above-mentioned main model, replacing $n$ Power with $n$ Affiliation or $n$ Achievement, respectively (we only give the $p$-levels here; please see the output on https://osf.io/afmrg for full test statistics). In both cases, the five-way overall model ceased to be significant ( $p=.42$ and .68 , respectively) and no other robust effects emerged.

Because Table 2 indicated positive relationships between long bone growth and $\mathrm{AI}$ in women generally, we averaged ulna and fibula length into a general indicator of long bone growth. While long bone growth was unrelated to AI overall $(r=.12$; $p=.18)$ and for men $(r=-.09 ; p=.50)$, it was related to AI for women $(r=.26$; $p=.03$ ). These findings did not substantially change when we controlled for variations in body height, suggesting a specific sex-dimorphic link between ulna and fibula length and AI. 


\section{Discussion}

Searching for a novel marker of organizing hormone effects on the motivational brain, we measured the long bones ulna and fibula. Both were sexually dimorphic, but after partialling out body height, only ulna was still dimorphic. Thus, we created an UFR, with the lower limb serving as a correcting variable for the signal-carrying upper limb. This also was preferable because while the upper limb in bipedal humans is able to grow somewhat unrestricted by external forces, the lower limb is almost continuously exposed to the pressure of a human's body weight. UFR was robustly dimorphic, with higher scores for men compared to women. We factored in potential laterality effects by creating $\mathrm{UFR}_{\mathrm{r}-\mathrm{l}}$, the difference between right-side and left-side UFR, which however was not dimorphic.

While Hypothesis 1 predicting a negative relationship between long bone length and $n$ Power was not supported, the relationship between UFR and $n$ Power differed between sexes, being negative for men and positive for women. In support of Hypothesis 2, we identified similar influencing variables for long bone growth as for 2D:4D (cf. Schultheiss et al. 2019) by finding a sex-dimorphic interaction of $n$ Power and AI on UFR asymmetry. High UFR $_{\mathrm{r}-1}$ scores were related to the IPM (high $n$ Power, high activity inhibition) in men, while for women the pattern was (non-significantly) reversed. Correlative and exploratory analyses yielded additional patterns like a sexdimorphic interaction of AI on long bone growth. As these results were unpredicted, we concentrate on the main findings regarding UFR and $n$ Power in the following.

\section{Interpretation}

\section{Long Bone Length as a Marker of Pubertal Organizing Hormone Effects}

In our view, our results suggest that long bone length, particularly the differential growth effect reflected in UFR, is a potential marker of pubertal organizing hormone effects. Research pertaining to forming limb ratios is rare, which is surprising given the very conserved mathematical relationships they yield (Pietak et al. 2013). And if such ratios are calculated, researchers often seem to focus on within-extremity ratios like between ulna and radius (or humerus) or between tibia and fibula (Brons et al. 1990; Pietak et al. 2013). To our best knowledge, there is no research concerning UFR specifically so far.

While our data favor forming an UFR, there are two more arguments regarding its potential value as a marker of organizing hormone effects. In our view, a marker's value is based on its attributability to a developmental window and, most importantly, on sexual dimorphism.

Several events during puberty converge on the conclusion that long bone length represents a window into hormonal effects during this life phase: The pubertal growth spurt doubles the growth rate of children and is responsible for more than $15 \%$ of adult body size - and in both sexes, this growth spurt is mainly driven by sex hormones (i.e., by estrogens; Cutler 1997). Even more important, puberty is the time of epiphyseal fusion and thus termination of long bone growth (Cutler 1997). Thus, variations in long bone length are closely linked to endocrine changes during puberty. 
Regarding sexual dimorphism, dimorphisms in large structures such as long bones should not only be visible to the naked eye, but also easier to replicate than the ones in smaller, subtle ratios like fWHR, whose dimorphism is doubtful (meta-analysis by Kramer 2017). Indeed, our UFR measure was dimorphic at $p=.003$ and even passes the stricter significance threshold of .005 for new discoveries proposed by many scientists (Benjamin et al. 2018).

With an effect size of $d=0.55$, the sex difference in UFR is similar to that of $2 \mathrm{D}: 4 \mathrm{D}$, which is also of medium strength (Hönekopp and Watson 2010; Manning et al. 2014). In addition, earlier research provided strong indications that relative upper and lower limb length is influenced by sex steroids: Men affected by Klinefelter syndrome (i.e. having an additional X-chromosome and low androgen levels) have a height advantage compared to normal men, but the growth of the legs is much more enhanced than that of the arms (Chang et al. 2015). While this supports our basic assumption of the role of sex steroids in epiphyseal fusion, UFR's marker function is also supported by the fact that those hypogonadic men thus show a more "female-typical" ratio. Even more, 2D:4D is also higher ("female-typical") in Klinefelter syndrome, while finger length relative to height is reduced (Manning et al. 2013). Future research will have to clarify whether UFR is not only dimorphic, but also perceived as a visual, potentially evolved, cue by conspecifics regarding dominance or mate value of an individual.

While $\mathrm{UFR}_{\mathrm{r}-1}$ was not dimorphic, it would be premature to discard it as a potential marker. First, the pathological femur-fibula-ulna complex, aplasia in femur and fibula and malformation of the ulnar part of the upper limb, occurs preferably unilaterally, on the right side of the body (Florio et al. 1999), pointing to a latent inherent asymmetry in long-bone development. Second, meta-analytic evidence regarding left-right differences in sexual dimorphism of 2D:4D (Hönekopp and Watson 2010) and the frequent usage of $\mathrm{D}_{\mathrm{r}-1}$ as a marker of its own in studies of 2D:4D (Manning et al. 2014), demand further investigation of asymmetries in any potential marker. Third, UFR $\mathrm{U}_{\mathrm{r}-1}$ presents pervasive relationships to fWHR as another possible marker of pubertal organizing hormone effects (but also to 2D:4D as a prenatal one). Finally, $\mathrm{UFR}_{\mathrm{r}-\mathrm{l}}$ is useful in explaining our results regarding the motivational brain (see below). This may indicate that $\mathrm{UFR}_{\mathrm{r}-1}$ reflects developmental processes beyond those captured by UFR.

\section{Long Bone Length and the Motivational Brain}

While there were no direct negative relationships between our target bones and $n$ Power, we found a sex-dimorphic relationship between UFR and $n$ Power. Our first intuition that E2-driven (or T-converted-to-E2-driven) epiphyseal closure signals the action of $n$ Power-relevant hormones on the motivational brain during puberty - was too simple. Hypothesis 1 did not consider the influence of sex on marker results in the betterpowered studies on prenatal (Schultheiss et al. 2019) and pubertal (Janson et al. 2018) organizing hormone effects on $n$ Power. In addition, marker research often uses ratios like 2D:4D or fWHR, not absolute lengths that may be largely dependent on body height, which was also true in our sample. Thus, our failure to support Hypothesis 1 is no surprise.

Nevertheless, the sex-dimorphic relationship between UFR and $n$ Power, taken together with the fWHR study by Janson et al. (2018), is additional evidence that the 
motivational brain, besides being influenced by prenatal hormones (Schultheiss et al. 2019; Schultheiss and Zimni 2015), undergoes a second window of steroidal organization during puberty (cf. Köllner et al. 2019). Hormone-sensitive subcortical nuclei in the anterior hypothalamus (Schultheiss 2013) may be the target of $n$ Power-defining organization, but we refrain from speculation for now.

Hypothesis 2 was supported. A combined pattern of bone, body side, sex, $n$ Power, and AI was related to long bone growth. This parallels findings regarding 2D:4D by Schultheiss et al. (2019). Most notably, similar to their Sex x $n$ Power x AI interaction on $\mathrm{D}_{\mathrm{r}-\mathrm{l}}$, we found a Sex $\mathrm{x} n$ Power $\mathrm{x}$ AI interaction on $\mathrm{UFR}_{\mathrm{r}-\mathrm{l}}$, underscoring the importance of taking body and brain asymmetry into account when exploring organizing hormone effects on the motivational brain. Finally, our findings diverged from those of Schultheiss et al. (2019) in the sense that in our study we found a marker of organizing hormonal effects - UFR $\mathrm{r}-1$ - to be related to the IPM in men, whereas these authors observed such an effect more strongly in women. Despite this subtle difference, we think that the overall convergence of our present findings with their earlier ones targeting 2D:4D (and also Janson et al.'s 2018, even though they did not include a measure of asymmetry) is encouraging and suggests that what we observe is not an isolated effect, but part of a consistent developmental pattern linking variations in $n$ Power to pervasive organizational effects of hormones.

The involvement of AI, which some view as a marker of brain laterality (Schultheiss et al. 2009), in all studies relating markers to $n$ Power so far and of body side in the largest study (Schultheiss et al. 2019) suggests that organizing hormones have an impact on body and brain lateralization during sensitive developmental windows (cf. Geschwind and Galaburda 1987). Our results for Hypothesis 2 involving body asymmetry and AI add further credibility to this idea. Hormone-dependent brain lateralization of the prefrontal cortex (PFC) as well as changes in cortical connectivity in this area during puberty may be involved (see Köllner et al. 2019, for details). However, such complex interactions demand more test power and replication studies - why exactly $n$ Power and AI are related to body morphology measures like UFR and 2D:4D in a lateralized manner and what patterns of brain lateralization this entails remains a riddle at this point and awaits clarification by brain imaging and/or neuropsychology (Schultheiss et al. 2019). We therefore refrain from postulating exact mechanisms, especially considering that $\mathrm{UFR}_{\mathrm{r}-1}$, our indicator of body asymmetry, was not dimorphic and that earlier, albeit low-powered $(N=20)$, pilot research did not find differences between left and right ulna measurements (Purkait 2001).

For now, we stick to the empirical evidence for 2D:4D, fWHR, and now also long bone length: The relevant observation is that there are replicable associations between marker scores and $n$ Power across different developmental windows. This likely reflects behavioral organization during the prenatal (2D:4D) and pubertal (fWHR, long bones) window in which organizing hormone effects simultaneously affect the development of the motivational brain and bodily growth. Our study adds converging evidence to the pubertal window using long bone length as a novel marker, especially via UFR. The highly significantly sex-dimorphic UFR can be assessed easily and reliably (Bleck 2018) and is associated with similar parameters as 2D:4D in designs involving implicit motives (cf. Schultheiss et al. 2019). However, this novel ratio measure emerged from the first study combining ulna and fibula measurement and motivational variables, a 
data-driven and thus partly exploratory approach, and from a cross-sectional correlational design. Thus, our results need large-sample-based replication.

\section{Limitations and Future Directions}

A limitation of our anthropometric approach is that other variables also influence marker scores (e.g., effects of BMI on fWHR, Lefevre et al. 2012), potentially reducing observed effects of organizing hormone effects. Skeletal growth is regulated by various metabolic processes and even the same hormone may influence various processes in different ways (Raisz and Kream 1981). Also, our non-invasive, body-surface-based measurement may have obscured the actual size of the relationships between motivational dispositions and bone length. This issue pertains to most marker-based studies, considering for example the modest correlation between 2D:4D measured via X-rays and from photocopies (Manning 2002). However, other influencing variables and random measurement error due to imprecise measurement would in all likelihood underestimate the actual size of the associations and thus attenuate, not amplify, the results reported here (cf. Köllner et al. 2019; Schultheiss et al. 2019).

Another issue which is not exclusive to our approach featuring long bones, but also pertains to other attempts to use morphometric markers like $2 \mathrm{D}: 4 \mathrm{D}$, is the confounding of the effects of androgen and estrogen action: In our case, this involves absolute information in terms of similar effects of T and E2 on bone growth per se, but possibly also simultaneous relative information about androgen versus estrogen action pertaining to the sex dimorphic ratio between ulna and fibula (consistent with the observations in men affected by Klinefelter syndrome). However, as animal research has shown (Zheng and Cohn 2011), this confounding also applies to 2D:4D, which only carries relative information in terms of the estrogen/androgen balance. This issue can only be conclusively resolved in the long run by assessing several sex hormones simultaneously during the respective developmental windows and then relating this specific information to specific markers in adults.

While our sample size was reasonably sound, deliberations regarding sample size were restricted by the requirements for bachelor's theses at our university and by the fact that there was no previously observed effect as a reference point. Preregistered replications in larger samples are all the more necessary, as the multiple comparisons involved in many of our analyses may have been susceptible to Type I errors in this context (Cramer et al. 2016).

While the above-mentioned aspects like the pubertal growth spurt and epiphyseal fusion strongly suggest that a possible marker function of long bone growth would apply to the pubertal developmental window, at present we cannot rule out prenatal contributions to UFR. Significant relationships of UFR's asymmetry to overall and left 2D:4D make such contributions in fact seem likely. However, questions when the sex-difference in UFR arises in ontogeny (possibly even as early as 2D:4D) or if it is replicably associated with other markers can only be clarified by further research in adults, but also in children and adolescents of varying ages and pubertal stages.

Finally, identifying body markers is just an intermediate step in exploring the relationships between brain development and behavior or personality. We should move 
on to directly looking at the brain itself in all studies where this is feasible (cf. Köllner et al. 2018). Brain imaging regarding structure, function, and connective tracts must clarify the currently unclear mechanisms of organizing hormone effects directly on the brain, circumventing the pitfalls of interpreting noisy peripheral markers of hormone action.

\section{Conclusions}

In sum, our findings indicate that $n$ Power is associated with body-morphological features that may be indicative of organizing hormone effects on the brain. In addition,

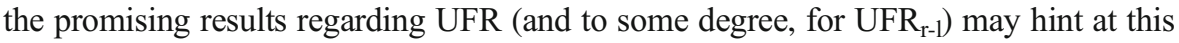
parameters' potential as an additional marker of organizational hormone effects that goes beyond facial or hand characteristics. The present findings converge with other power-motive-related results for the prenatal and the pubertal window emerging from well-powered, multi-study research on 2D:4D (Schultheiss et al. 2019; $N=618$ ) and fWHR (Janson et al. 2018, $N=213$ ) which involve the same effect-constituting variables as our results. Future studies will show if UFR produces replicable robust results in conjunction with implicit motives and other dispositions and behaviors.

Open Science All data files, the study logbook, analysis scripts for reported results, as well as the output files associated with this research are available at https://osf. io/afmrg/. Changes or corrections will be acknowledged in the file "post-publication changes" there.

Acknowledgements Open Access funding provided by Projekt DEAL. We thank Oliver C. Schultheiss for helpful comments on previous versions of this manuscript. We also thank Franziska Jägel and Julia Fenkl for their involvement in designing the ulna and fibula measurement protocols, recruiting participants and conducting the experiment. Julia Fenkl also coded the PSEs and Franziska Jägel measured 2D:4D from handscans for Footnote 3. In addition, we want to thank our anonymous reviewers for their invaluable contributions to our understanding and presentation of our findings. Portions of this article were presented as a poster at the 36th Colloquium on Motivational Psychology (Bleck et al. 2016). Parts of the results were reported in KB's unpublished bachelor's thesis and the reliability checks for bone lengths mentioned in the methods section are featured in her long bone measurement instructions that supplement this article (Bleck 2018). The PSE data in this article was also used in the two-study aggregation by Janson et al. (2018), but with a different research question.

Author Contributions MGK wrote the manuscript and designed the study. KB refined the manuscript, recruited participants, conducted the experiment, and coded the PSEs. Both authors designed the measurement protocols and undertook the statistical analysis. Both authors contributed to and have approved the final manuscript.

Funding Information This research did not receive any specific grant from funding agencies in the public, commercial, or not-for-profit sectors.

\section{Compliance with Ethical Standards}

All conducted experiments comply with the current laws of Germany. All participants gave their informed consent prior to their inclusion in the studies. The manuscript does not contain clinical studies or patient data. 
Conflict of Interest The authors declare that they have no conflict of interest.

Open Access This article is licensed under a Creative Commons Attribution 4.0 International License, which permits use, sharing, adaptation, distribution and reproduction in any medium or format, as long as you give appropriate credit to the original author(s) and the source, provide a link to the Creative Commons licence, and indicate if changes were made. The images or other third party material in this article are included in the article's Creative Commons licence, unless indicated otherwise in a credit line to the material. If material is not included in the article's Creative Commons licence and your intended use is not permitted by statutory regulation or exceeds the permitted use, you will need to obtain permission directly from the copyright holder. To view a copy of this licence, visit http://creativecommons.org/licenses/by/4.0/.

\section{References}

Atkinson, J. W. (1957). Motivational determinants of risk-taking behavior. Psychological Review, 64(6, Pt.1), 359-372. https://doi.org/10.1037/h0043445.

Benjamin, D. J., Berger, J. O., Johannesson, M., Nosek, B. A., Wagenmakers, E.-J., Berk, R., Bollen, K. A., Brembs, B., Brown, L., Camerer, C., Cesarini, D., Chambers, C. D., Clyde, M., Cook, T. D., de Boeck, P., Dienes, Z., Dreber, A., Easwaran, K., Efferson, C., Fehr, E., Fidler, F., Field, A. P., Forster, M., George, E. I., Gonzalez, R., Goodman, S., Green, E., Green, D. P., Greenwald, A. G., Hadfield, J. D., Hedges, L. V., Held, L., Hua Ho, T., Hoijtink, H., Hruschka, D. J., Imai, K., Imbens, G., Ioannidis, J. P. A., Jeon, M., Jones, J. H., Kirchler, M., Laibson, D., List, J., Little, R., Lupia, A., Machery, E., Maxwell, S. E., McCarthy, M., Moore, D. A., Morgan, S. L., Munafó, M., Nakagawa, S., Nyhan, B., Parker, T. H., Pericchi, L., Perugini, M., Rouder, J., Rousseau, J., Savalei, V., Schönbrodt, F. D., Sellke, T., Sinclair, B., Tingley, D., van Zandt, T., Vazire, S., Watts, D. J., Winship, C., Wolpert, R. L., Xie, Y., Young, C., Zinman, J., \& Johnson, V. E. (2018). Redefine statistical significance. Nature Human Behaviour, 2, 6-10. https://doi.org/10.1038/s41562-017-0189-z.

Bleck, K. (2018). Measuring lengths of ulna and fibula in living individuals. Retrieved from http://www. psych2.phil.uni-erlangen.de/\%7Eoschult/humanlab/resources/resources_Ulna_Fibula.htm. Accessed 15 Jan 2020.

Bleck, K., Fenkl, J., Jägel, F., \& Köllner, M. G. (2016). Zusammenhänge zwischen dem impliziten Machtmotiv, Steroidhormonen und Längen der Ulna und Fibula [Relationships between the implicit power motive, steroid hormones, and length of ulna and fibula]. Poster presented at the $36^{\text {th }}$ colloquium on motivational psychology, Erlangen (Germany).

Borsboom, D., Mellenbergh, G. J., \& van Heerden, J. (2004). The concept of validity. Psychological Review, 111(4), 1061-1071. https://doi.org/10.1037/0033-295x.111.4.1061.

Brons, J. T. J., van der Harten, J. J., van Geijn, H. P., Wladimiroff, J. W., Reuss, A., Stewart, P., Meijer, C. J. L. M., \& Arts, N. F. T. (1990). Ratios between growth parameters for the prenatal ultrasonographic diagnosis of skeletal dysplasias. European Journal of Obstetrics \& Gynecology and Reproductive Biology, 34, $37-$ 46. https://doi.org/10.1016/0028-2243(90)90005-L.

Callewaert, F., Sinnesael, M., Gielen, E., Boonen, S., \& Vanderschueren, D. (2010). Skeletal sexual dimorphism: Relative contribution of sex steroids, GH-IGF1, and mechanical loading. Journal of Endocrinology, 207, 127-134. https://doi.org/10.1677/JOE-10-0209.

Carré, J. M., \& McCormick, C. M. (2008). In your face: Facial metrics predict aggressive behaviour in the laboratory and in varsity and professional hockey players. Proceedings of the Royal Society B, 275, 26512656. https://doi.org/10.1098/rspb.2008.0873.

Chang, S., Skakkebæk, A., Trolle, C., Bojesen, A., Hertz, J. M., Cohen, A., Hougaard, D. M., Wallentin, M., Pedersen, A. D., Østergaard, J. R., \& Gravholt, C. H. (2015). Anthropometry in Klinefelter syndrome multifactorial influences due to CAG length, testosterone treatment and possibly intrauterine hypogonadism. The Journal of Clinical Endocrinology and Metabolism, 100(3), E508-E517. https://doi.org/10.1210/jc.2014-2834.

Connelly, K. J., Larson, E. A., Marks, D. L., \& Klein, R. F. (2015). Neonatal estrogen exposure results in biphasic age-dependent effects on the skeletal development of male mice. Endocrinology, 156(1), 193202. https://doi.org/10.1210/en.2014-1324. 
Cramer, A. O. J., Ravenzwaaij, D. v., Matzke, D., Steingroever, H., Wetzels, R., Grasman, R. P. P. P., et al. (2016). Hidden multiplicity in exploratory multiway ANOVA: Prevalence and remedies. Psychonomic Bulletin \& Review, 23, 640-647. https://doi.org/10.3758/s13423-015-0913-5.

Cutler, G. B. (1997). The role of estrogen in bone growth and maturation during childhood and adolescence. The Journal of Steroid Biochemistry and Molecular Biology, 61(3-6), 141-144. https://doi.org/10.1016 /S0960-0760(97)80005-2.

Deaner, R. O., Goetz, S. M. M., Shattuck, K., \& Schnotala, T. (2012). Body weight, not facial width-to-height ratio, predicts aggression in pro hockey players. Journal of Research in Personality, 46(2), 235-238. https://doi.org/10.1016/j.jrp.2012.01.005.

Drescher, A., \& Schultheiss, O. C. (2016). Meta-analytic evidence for higher implicit affiliation and intimacy motivation scores in women, compared to men. Journal of Research in Personality, 64, 1-10. https://doi. org/10.1016/j.jrp.2016.06.019.

Fink, B., Neave, N., \& Manning, J. T. (2003). Second to fourth digit ratio, body mass index, waist-to-hip ratio, and waist-to-chest ratio: Their relationships in heterosexual men and women. Annals of Human Biology, 30(6), 728-738. https://doi.org/10.1080/03014460310001620153.

Florio, I., Wisser, J., Huch, R., \& Huch, A. (1999). Prenatal ultrasound diagnosis of a femur-fibula-ulna complex during the first half of pregnancy. Fetal Diagnosis and Therapy, 14, 310-312. https://doi. org/10.1159/000020946.

Frisch, M., \& Schultheiss, O. C. (2012). PSECoder software. Erlangen: Author.

Geniole, S. N., Denson, T. F., Dixson, B. J., Carré, J. M., \& McCormick, C. M. (2015). Evidence from metaanalyses of the facial width-to-height ratio as an evolved cue of threat. PLoS One, 10(7), e0132726. https://doi.org/10.1371/journal.pone.0132726.

Geschwind, N., \& Galaburda, A. M. (1987). Cerebral lateralization: Biological mechanisms, associations, and pathology. Cambridge: MIT Press.

Haselhuhn, M. P., Ormiston, M. E., \& Wong, E. M. (2015). Men's facial width-to-height ratio predicts aggression: A meta-analysis. PLoS One, 10(4), e0122637. https://doi.org/10.1371/journal.pone.0122637.

Hehman, E., Leitner, J. B., \& Freeman, J. B. (2014). The face-time continuum: Lifespan changes in facial width-to-height ratio impact aging-associated perceptions. Personality and Social Psychology Bulletin, 40(12), 1624-1636. https://doi.org/10.1177/0146167214552791.

Hönekopp, J., \& Schuster, M. (2010). A meta-analysis on 2D:4D and athletic prowess: Substantial relationships but neither hand out-predicts the other. Personality and Individual Differences, 48(1), 4-10. https://doi.org/10.1016/j.paid.2009.08.009.

Hönekopp, J., \& Watson, S. (2010). Meta-analysis of digit ratio 2D:4D shows greater sex difference in the right hand. American Journal of Human Biology, 22, 619-630. https://doi.org/10.1002/ajhb.21054.

Hönekopp, J., Bartholdt, L., Beier, L., \& Liebert, A. (2007). Second to fourth digit length ratio (2D:4D) and adult sex hormone levels: New data and a meta-analytic review. Psychoneuroendocrinology, 32, 313-321. https://doi.org/10.1016/j.psyneuen.2007.01.007.

Janson, K. T., Bleck, K., Fenkl, J., Riegl, L. T., Jägel, F., \& Köllner, M. G. (2018). Inhibited power motivation is associated with the facial width-to-height ratio in females. Adaptive Human Behavior and Physiology, 4(1), 21-41. https://doi.org/10.1007/s40750-017-0075-y.

Jemmott, J. B. (1987). Social motives and susceptibility to disease: Stalking individual differences in health risks. Journal of Personality, 55(2), 267-298. https://doi.org/10.1111/j.1467-6494.1987.tb00437.x.

Juul, A. (2001). The effects of oestrogens on linear bone growth. Human Reproduction Update, 7(3), 303313. https://doi.org/10.1111/j.1600-0463.2001.tb05758.x.

Kherdjemil, Y., Lalonde, R. L., Sheth, R., Dumouchel, A., Martino, G. d., Pineault, K. M., et al. (2016). Evolution of Hoxa11 regulation in vertebrates is linked to the pentadactyl state. Nature, 539, 89-92. https://doi.org/10.1038/nature19813.

Köllner, M. G. (2015). The influence of implicit motives on implicit instrumental conditioning: Testing a principle focusing on the power motive. (doctoral dissertation), Friedrich-Alexander University ErlangenNürnberg, Erlangen, Germany. Retrieved from http://d-nb.info/1079385363.

Köllner, M. G., \& Janson, K. T. (2017). The sociobiological development and arousal of implicit motives: The emergence of a growth-and-prune model of motive development and the continued linkage of hormones and motives throughout the life span. Psychoneuroendocrinology, 83S, 70. https://doi.org/10.1016/j. psyneuen.2017.07.426.

Köllner, M. G., \& Schultheiss, O. C. (2014). Meta-analytic evidence of low convergence between implicit and explicit measures of the needs for achievement, affiliation, and power. Frontiers in Psychology, 5(826). https://doi.org/10.3389/fpsyg.2014.00826. 
Köllner, M. G., Janson, K. T., \& Schultheiss, O. C. (2018). Commentary: Sexual dimorphism of facial widthto-height ratio in human skulls and faces: A meta-analytical approach. Frontiers in Endocrinology, 9(227). https://doi.org/10.3389/fendo.2018.00227.

Köllner, M. G., Janson, K. T., \& Bleck, K. (2019). The social biopsychology of implicit motive development. In O. C. Schultheiss \& P. H. Mehta (Eds.), Routledge international handbook of social neuroendocrinology (pp. 568-585). Abingdon: Routledge.

Kramer, R. S. S. (2017). Sexual dimorphism of facial width-to-height ratio in human skulls and faces: A metaanalytical approach. Evolution and Human Behavior, 38(3), 414-420. https://doi.org/10.1016/j. evolhumbehav.2016.12.002.

Lefevre, C. E., Lewis, G. J., Bates, T. C., Dzhelyova, M., Coetzee, V., Deary, I. J., \& Perrett, D. I. (2012). No evidence for sexual dimorphism of facial width-to-height ratio in four large adult samples. Evolution and Human Behavior, 33(6), 623-627. https://doi.org/10.1016/j.evolhumbehav.2012.03.002.

Leslie, M. (2019). The mismeasure of hands. Science, 364(6444), 923-925. https://doi.org/10.1126 /science.364.6444.923.

Lutchmaya, S., Baron-Cohen, S., Raggatt, P., Knickmeyer, R., \& Manning, J. T. (2004). 2nd to 4th digit ratios, fetal testosterone and estradiol. Early Human Development, 77, 23-28. https://doi.org/10.1016/j. earlhumdev.2003.12.002.

Manning, J. T. (2002). Digit ratio. A pointer to fertility, behavior, and health. New Brunswick: Rutgers University Press.

Manning, J. T., \& Fink, B. (2008). Digit ratio (2D:4D), dominance, reproductive success, asymmetry, and sociosexuality in the BBC internet study. American Journal of Human Biology, 20, 451-461. https://doi. org/10.1002/ajhb.20767.

Manning, J. T., Scutt, D., Wilson, J., \& Lewis-Jones, D. I. (1998). The ratio of 2nd to 4th digit length: A predictor of sperm numbers and concentrations of testosterone, luteinizing hormone and oestrogen. Human Reproduction, 13(11), 3000-3004. https://doi.org/10.1093/humrep/13.11.3000.

Manning, J. T., Kilduff, L. P., \& Trivers, R. (2013). Digit ratio (2D:4D) in Klinefelter's syndrome. Andrology, 1, 94-99. https://doi.org/10.1111/j.2047-2927.2012.00013.x.

Manning, J. T., Kilduff, L., Cook, C., Crewther, B., \& Fink, B. (2014). Digit ratio (2D:4D): A biomarker for prenatal sex steroids and adult sex steroids in challenge situations. Frontiers in Endocrinology, 5(9). https://doi.org/10.3389/fendo.2014.00009.

Martin, J. T., \& Nguyen, D. H. (2004). Anthropometric analysis of homosexuals and heterosexuals: Implications for early hormone exposure. Hormones and Behavior, 45(1), 31-39. https://doi. org/10.1016/j.yhbeh.2003.07.003.

McClelland, D. C., \& Boyatzis, R. E. (1982). Leadership motive pattern and long-term success in management. Journal of Applied Psychology, 67(6), 737-743. https://doi.org/10.1037/0021-9010.67.6.737.

McClelland, D. C., Floor, E., Davidson, R. J., \& Saron, C. (1980). Stressed power motivation, sympathetic activation, immune function, and illness. Journal of Human Stress, 6(2), 11-19. https://doi.org/10.1080 /0097840X.1980.9934531.

McClelland, D. C., Koestner, R., \& Weinberger, J. (1989). How do self-attributed and implicit motives differ? Psychological Review, 96(4), 690-702. https://doi.org/10.1037/0033-295x.96.4.690.

Ober, C., Loisel, D. A., \& Gilad, Y. (2008). Sex-specific genetic architecture of human disease. Nature Reviews Genetics, 9, 911-922. https://doi.org/10.1038/nrg2415.

Pang, J. S., \& Schultheiss, O. C. (2005). Assessing implicit motives in U.S. college students: Effects of picture type and position, gender and ethnicity, and cross-cultural comparisons. Journal of Personality Assessment, 85(3), 280-294. https://doi.org/10.1207/s15327752jpa8503_04.

Phoenix, C. H., Goy, R. W., Gerall, A. A., \& Young, W. C. (1959). Organizing action of prenatally administered testosterone propionate on the tissues mediating mating behavior in the female Guinea pig. Endocrinology, 65(3), 369-382. https://doi.org/10.1210/endo-65-3-369.

Pietak, A., Ma, S., Beck, C. W., \& Stringer, M. D. (2013). Fundamental ratios and logarithmic periodicity in human limb bones. Journal of Anatomy, 222, 526-537. https://doi.org/10.1111/joa.12041.

Purkait, R. (2001). Measurements of ulna-A new method for determination of sex. Journal of Forensic Sciences, 46(4), 924-927. https://doi.org/10.1520/JFS15071J.

Raisz, L. G., \& Kream, B. E. (1981). Hormonal control of skeletal growth. Annual Review of Physiology, 43, 225-238. https://doi.org/10.1146/annurev.ph.43.030181.001301.

Reuman, D. A. (1982). Ipsative behavioral variability and the quality of thematic apperceptive measurement of the achievement motive. Journal of Personality and Social Psychology, 43(5), 1098-1110. https://doi. org/10.1037/0022-3514.43.5.1098.

Russell, G. F. M. (1985). Premenarchal anorexia nervosa and its sequelae. Journal of Psychiatric Research, 19(2/3), 363-369. https://doi.org/10.1016/0022-3956(85)90041-X. 
Sacragi, A., \& Ikeda, T. (1995). Sex identification from the distal fibula. International Journal of Osteoarchaeology, 5, 139-143. https://doi.org/10.1002/oa.1390050205.

Schultheiss, O. C. (2009). German-language training and calibration materials for Winter's (1994) manual for scoring motive imagery in running text. Erlangen: Department of psychology, Friedrich-Alexander University. Unpublished manuscript.

Schultheiss, O. C. (2013). The hormonal correlates of implicit motives. Social and Personality Psychology Compass, 7(1), 52-65. https://doi.org/10.1111/spc3.12008.

Schultheiss, O. C. (2017). Evidence for prenatal organizational effects of steroids on the motivational brain. Psychoneuroendocrinology, 83S, 69. https://doi.org/10.1016/j.psyneuen.2017.07.423.

Schultheiss, O. C., \& Brunstein, J. C. (2002). Inhibited power motivation and persuasive communication: A lens model analysis. Journal of Personality, 70(4), 553-582. https://doi.org/10.1111/1467-6494.05014.

Schultheiss, O. C., \& Köllner, M. G. (2014). Implicit motives, affect, and the development of competencies: A virtuous-circle model of motive-driven learning. In R. Pekrun \& L. Linnenbrink-Garcia (Eds.), International handbook of emotions in education (pp. 73-95). New York: Taylor \& Francis/Routledge.

Schultheiss, O. C., \& Köllner,M. G. (2020). Implicit motives. In O. P. John \& R.W. Robins (Eds.), Handbook of personality: Theory and research (4th ed.). New York: Guilford Press.

Schultheiss, O. C., \& Pang, J. S. (2007). Measuring implicit motives. In R. W. Robins, R. C. Fraley, \& R. F. Krueger (Eds.), Handbook of research methods in personality psychology (pp. 322-344). New York: Guilford Press.

Schultheiss, O. C., \& Schultheiss, M. (2014). Implicit motive profile analysis: An if-then contingency approach to the picture-story exercise. Social and Personality Psychology Compass, 8(1), 1-16. https://doi.org/10.1111/spc3.12082.

Schultheiss, O. C., \& Zimni, M. (2015). Associations between implicit motives and salivary steroids, 2D:4D digit ratio, mental rotation performance, and verbal fluency. Adaptive Human Behavior and Physiology, 1, 387-407. https://doi.org/10.1007/s40750-014-0012-2.

Schultheiss, O. C., Wirth, M. M., Torges, C. M., Pang, J. S., Villacorta, M. A., \& Welsh, K. M. (2005). Effects of implicit power motivation on men's and women's implicit learning and testosterone changes after social victory or defeat. Journal of Personality and Social Psychology, 88(1), 174-188. https://doi.org/10.1037 /0022-3514.88.1.174.

Schultheiss, O. C., Riebel, K., \& Jones, N. M. (2009). Activity inhibition: A predictor of lateralized brain function during stress? Neuropsychology, 23(3), 392-404. https://doi.org/10.1037/a0014591.

Schultheiss, O. C., Patalakh, M., Rawolle, M., Liening, S., \& MacInnes, J. J. (2011). Referential competence is associated with motivational congruence. Journal of Research in Personality, 45(1), 59-70. https://doi. org/10.1016/j.jrp.2010.11.014.

Schultheiss, O. C., Frisch, M., Özbe, D., Ossmann, A., Schultheiss, M., Lentz, S., Martin, L., \& Rösch, A. G. (2019). Implicit motives show sex-dimorphic associations with digit ratio. Motivation Science, 5(4), 326342. https://doi.org/10.1037/mot0000122.

Schulz, K. M., \& Sisk, C. L. (2016). The organizing actions of adolescent gonadal steroid hormones on brain and behavioral development. Neuroscience and Biobehavioral Reviews, 70, 148-158. https://doi. org/10.1016/j.neubiorev.2016.07.036.

Shirazi, T. N., Self, H., Cantor, J., Dawood, K., Cárdenas, R., Rosenfield, K., et al. (2020). Timing of peripubertal steroid exposure predicts visuospatial cognition in men: Evidence from three samples. Hormones and Behavior, 121. https://doi.org/10.1016/j.yhbeh.2020.104712.

Sisk, C. L., \& Zehr, J. L. (2005). Pubertal hormones organize the adolescent brain and behavior. Frontiers in Neuroendocrinology, 26, 163-174. https://doi.org/10.1016/j.yfrne.2005.10.003.

Smith, C. P. (1992). Motivation and personality: Handbook of thematic content analysis. New York: Cambridge University Press.

Spangler, W. D. (1992). Validity of questionnaire and TAT measures of need for achievement: Two metaanalyses. Psychological Bulletin, 112(1), 140-154. https://doi.org/10.1037/0033-2909.112.1.140.

Stanton, S. J., \& Schultheiss, O. C. (2007). Basal and dynamic relationships between implicit power motivation and estradiol in women. Hormones and Behavior, 52(5), 571-580. https://doi.org/10.1016/j. yhbeh.2007.07.002.

Steinmann, B., Dörr, S. L., Schultheiss, O. C., \& Maier, G. W. (2015). Implicit motives and leadership performance revisited: What constitutes the leadership motive pattern? Motivation and Emotion, 39(2), 167-174. https://doi.org/10.1007/s11031-014-9458-6.

Stumpf, H., Angleitner, A., Wieck, T., Jackson, D. N., \& Beloch-Till, H. (1985). Deutsche personality research form [German personality research form]. Göttingen: Hogrefe.

Vanderschueren, D., Vandenput, L., Boonen, S., Lindberg, M. K., Bouillon, R., \& Ohlsson, C. (2004). Androgens and bone. Endocrine Reviews, 25(3), 389-425. https://doi.org/10.1210/er.2003-0003. 
Weston, E. M., Friday, A. E., \& Liò, P. (2007). Biometric evidence that sexual selection has shaped the hominin face. PLoS One, 2(8), e710. https://doi.org/10.1371/journal.pone.0000710.

Winter, D. G. (1993). Power, affiliation, and war: Three tests of a motivational model. Journal of Personality and Social Psychology, 65(3), 532-545. https://doi.org/10.1037/0022-3514.65.3.532.

Winter, D. G. (1994). Manual for scoring motive imagery in running text (4th ed.). Ann Arbor: Department of Psychology, University of Michigan Unpublished manuscript.

Zheng, Z., \& Cohn, M. J. (2011). Developmental basis of sexually dimorphic digit ratios. Proceedings of the National Academy of Sciences, 108(39), 16289-16294. https://doi.org/10.1073/pnas.1108312108.

Publisher's Note Springer Nature remains neutral with regard to jurisdictional claims in published maps and institutional affiliations.

\section{Affiliations}

\section{Martin G. Köllner ${ }^{1}$ - Kira Bleck ${ }^{1,2}$}

Kira Bleck

kira.bleck@fau.de

1 Human Motivation and Affective Neuroscience Lab, Department of Psychology, Institute of Psychology, Friedrich-Alexander University, Nägelsbachstrasse 49b, 91052 Erlangen, Germany

2 Present address: Universität Mannheim, Schloss, 68131 Mannheim, Germany 